\title{
Effectiveness of Clinician Client Centered Counseling on HIV Knowledge and Attitudes of Adult HIVIAIDS Patients Enrolled in Care in Yola, Nigeria: A Randomized Clinical Trial
}

\author{
Olutayo Folashade Martins ${ }^{1,}$, , Lekhraj Rampal ${ }^{2}$, Lye Munn-Sann², Sherina Mohd Sidik, \\ Norlijah Othman ${ }^{4}$, Zubairu Iliyasu ${ }^{5}$, Fatai Kunle Salawu ${ }^{1}$ \\ ${ }^{1}$ Department of Medicine, Federal Medical Center, Yola, Nigeria \\ ${ }^{2}$ Department of Community Health, Faculty of Medicine and health sciences, Universiti Putra Malaysia, Serdang, Selangor, Malaysia \\ ${ }^{3}$ Department of Psychiatry, Faculty of Medicine and health sciences, Universiti Putra Malaysia, Serdang, Selangor, Malaysia \\ ${ }^{4}$ Department of Pediatrics, Faculty of Medicine and health sciences, Universiti Putra Malaysia, Serdang, Selangor, Malaysia \\ ${ }^{5}$ Department of Community Medicine, Aminu Kano Teaching Hospital, Kano, Nigeria
}

\section{Email address:}

tymartins@yahoo.com (O. F. Martins),dr_rampal@hotmail.com (L. Rampal), lyems9@yahoo.com (L. Munn-Sann), sherina@upm.edu.my (S. M. Sidik), dean.medic@upm.edu.my (N. Othman), ziliyasu@gmail.com (Z. Iliyasu),

dr_abdulsalawu@yahoo.com (F. K. Salawu)

${ }^{*}$ Corresponding author

\section{To cite this article:}

Olutayo Folashade Martins, Lekhraj Rampal, Lye Munn-Sann, Sherina Mohd Sidik, Norlijah Othman, Zubairu Iliyasu, Fatai Kunle Salawu. Effectiveness of Clinician Client Centered Counseling on HIV Knowledge and Attitudes of Adult HIV/AIDS Patients Enrolled in Care in Yola, Nigeria: A Randomized Clinical Trial. European Journal of Preventive Medicine. Vol. 4, No. 3, 2016, pp. 85-94. doi: 10.11648/j.ejpm.20160403.16

Received: April 13, 2016; Accepted: April 25, 2016; Published: May 11, 2016

\begin{abstract}
This study assessed the effectiveness of a clinician client centered counseling on HIV knowledge and attitudes towards HIV/AIDS of adult HIV positive patients enrolled in care in Yola, Nigeria. The study was a 3 arm randomized single blind clinical trial involving 386 randomly selected and allocated adult HIV patients who were enrolled into ART at the 4 comprehensive ART sites in Yola. A clinician client centered training module was developed based on the Information Behavior and Motivation (IBM) Model. Nine Clinicians involved in ART care were trained with this module to deliver a 10 to 15 minutes clinic based intervention (Clinician Client Centered counseling). Intervention group 1 received two counseling sessions; at baseline and at 2 months. Intervention group 2 received one counseling session at baseline and the control group received routine care. An interviewer administered validated and structured questionnaire was used for data collection. Data was collected at baseline, 2 months and 6 months. Outcome measures were knowledge on HIV transmission and prevention and attitude towards HIVAIDS. Significant main effects for groups $(F(2,331)=17.410, p=0.0001)$, time $(F(2)=49.826, p=$ 0.0001, partial $\left.\dot{\eta}^{2}=0.134\right)$ and group-time interaction $\left(\mathrm{F}(2,331)=4.239, \mathrm{p}=0.015\right.$, partial $\left.\dot{\eta}^{2}=0.026\right)$ were seen for HIV knowledge scores. Significant main effects were seen for groups $\left(F(2)=11.107, p=0.021\right.$, partial $\left.\dot{\eta}^{2}=0.065\right)$ and time $(F(2)$ $=34.088, p=0.0001$, partial $\left.\dot{\eta}^{2}=0.096\right)$ for HIV attitudes scores. Clinician client centered counseling is effective in improving knowledge on HIV transmission and prevention and attitudes towards HIV/AIDS.
\end{abstract}

Keywords: Counseling, Behavioral Intervention, Knowledge, Attitudes, HIV/AIDS, Adult Patients Living with HIV, Nigeria 


\section{Introduction}

An estimated 34.0 million people are presently known to be living with HIV/AIDS globally [1]. This epidemic varies considerably between countries and regions with Sub Saharan Africa remaining the most severely affected [1]. Nearly 1 in 20 adults (4.9\%) are living with HIV in SubSaharan Africa and this account for about $69 \%$ of the global burden [1]. Nigeria has a HIV prevalence of $4.1 \%$ [2], which accounts for about 3.2 Million Nigerians out of which 2.8 Million are aged 15 years and above [3]. Adamawa state is located in the north- east of Nigeria. Yola is the capital of Adamawa state and has a prevalence of 3.8\% [2].

HIV transmission in Nigeria is primarily via heterosexual sex and accounts for $80-95 \%$ of HIV infections in the country [4]. Cases of AIDS are very visible in Nigeria. One out of every four persons in the country has seen someone with HIV or has known someone who died of AIDS. HIV awareness in Nigeria is high (93.8\%), however correct knowledge on all routes of possible transmission and methods of prevention have remained low (54\% and $52.5 \%$ respectively) [5], with people living with HIV/AIDS (PLWHAs) having low attitudes towards life and the disease itself.

Preventing the spread of HIV/AIDS can only be possible with sound knowledge on the various modes of transmission and spread of the disease among the general populace but more specifically, the people living with the disease. Though several studies have assessed the level of HIV knowledge among individuals who are HIV negative or of unknown status [6, 7, 8] and other studies have assessed the effectiveness of various educational interventions at improving HIV knowledge and attitudes towards HIV/AIDS among this same group of individuals [9], there is paucity of research that has assessed the level of knowledge of HIV transmission and prevention or effectiveness of interventions aimed at improving HIV knowledge and attitudes among people living with HIV/AIDS (PLWHAs) in Nigeria.

This paper describes the effectiveness of a clinician centered client counseling on knowledge of HIV prevention and transmission, and attitudes towards HIV/AIDS of adult HIV positive patients enrolled in care at the 4 comprehensive ART sites in Yola, north-eastern Nigeria.

\section{Materials and Methods}

Parts of the methodology of this research have been previously published along with baseline results of this research $[10,11]$.

This study was a 3 arm randomized single blind clinical trial involving 386 randomly selected and allocated adult HIV patients who were enrolled into Antiretroviral Therapy (ART) care at all 4 comprehensive ART sites in Yola. These comprehensive sites were the; Federal Medical Centre (FMC) Yola, State Specialist Hospital Yola (SSHY), St Francis Hospital Jambutu and Adamawa Hospital. The study took place from January to September 2014. A Clinician Client Centered training module was developed based on the Information Behavior and Motivation (IBM) Model.[12] Nine clinicians involved in ART care were trained with this module to deliver a 10 to 15 minutes clinic based intervention (Clinician Client Centered (CCC) counseling). Intervention group 1 received 2 counseling sessions; at baseline then at 2 months. Intervention group 2 received 1 counseling session at baseline only and the control group received routine care. Routine care at all sites involves group counseling sessions that hold on clinic days. Primary focus of these counseling sessions are; drug adherence, HIV prevention and transmission, and other topical issue which may arise during the sessions. However every HIV positive patient receives a pre test and post test counseling session at time of diagnosis. Follow up was at 2 months and 6 months.

\subsection{Participant Selection Criteria and Recruitment}

Criteria for inclusion into this study included all persons diagnosed with HIV $\geq 18$ years of age presenting to the 4 comprehensive ART clinics in Yola. Patients excluded from this study were those patients who were HIV positive but diagnosed with psychiatric disorders and were mentally incapacitated.

\subsection{Sample Size}

The sample size was calculated using the formula by Lemeshow et al [13]. Estimations were done for all outcome variables of this research. These variables were; HIV knowledge, attitudes towards HIV/AIDS, condom use, multiple sexual partners and HIV status disclosure.

The largest sample size was obtained for the outcome variable of attitude towards HIV/AIDS. Prevalence of positive attitudes towards HIV/AIDS of PLWHAs in Nigeria is $79.3 \%$ [14]. A prevalence of $90 \%$ positive attitude towards HIV/AIDS was desired. An initial sample size of 117 was obtained per group making a total of 351 for the 3 groups. Taking into account $10 \%$ for attrition the final sample size was 386. Probability proportionate to the size of adult patients living with HIV enrolled in care at each comprehensive ART site was used to allocate the number of participants recruited at each site.

Systematic sampling method was used to select participants at each site on every clinic day during the recruitment period. The sample frame was the patient register in the ART clinic at each recruitment site. A sampling interval was calculated for each site using the allocated sample size and average attendance. The first participant was recruited at each site by balloting; a member of the research team was asked to choose a lucky number between numbers 1 and the site's sampling interval. The patient whose serial number corresponds with the chosen number was the first to be selected at the site. This process was done at all study sites. Subsequent respondents were those whose serial numbers correspond with the previous respondent's plus sampling 
interval of the site.

At the recruitment sites, a total of 526 HIV positive patients were assessed for their eligibility out of which 140 were excluded. Reasons for exclusion included 56 patients who did not meet inclusion criteria $(50$ children and 6 mentally unfit) and 60 patients who declined consent. Twenty four others excluded for other reasons included 20 patients who intended to transfer out to other ART care clinics outside Yola (the study area) and 4 pregnant women who expected to give birth during the period of the research and believed that their deliveries may affect compliance with the study protocol. Eligible patients who gave their consent were randomized and blinded.
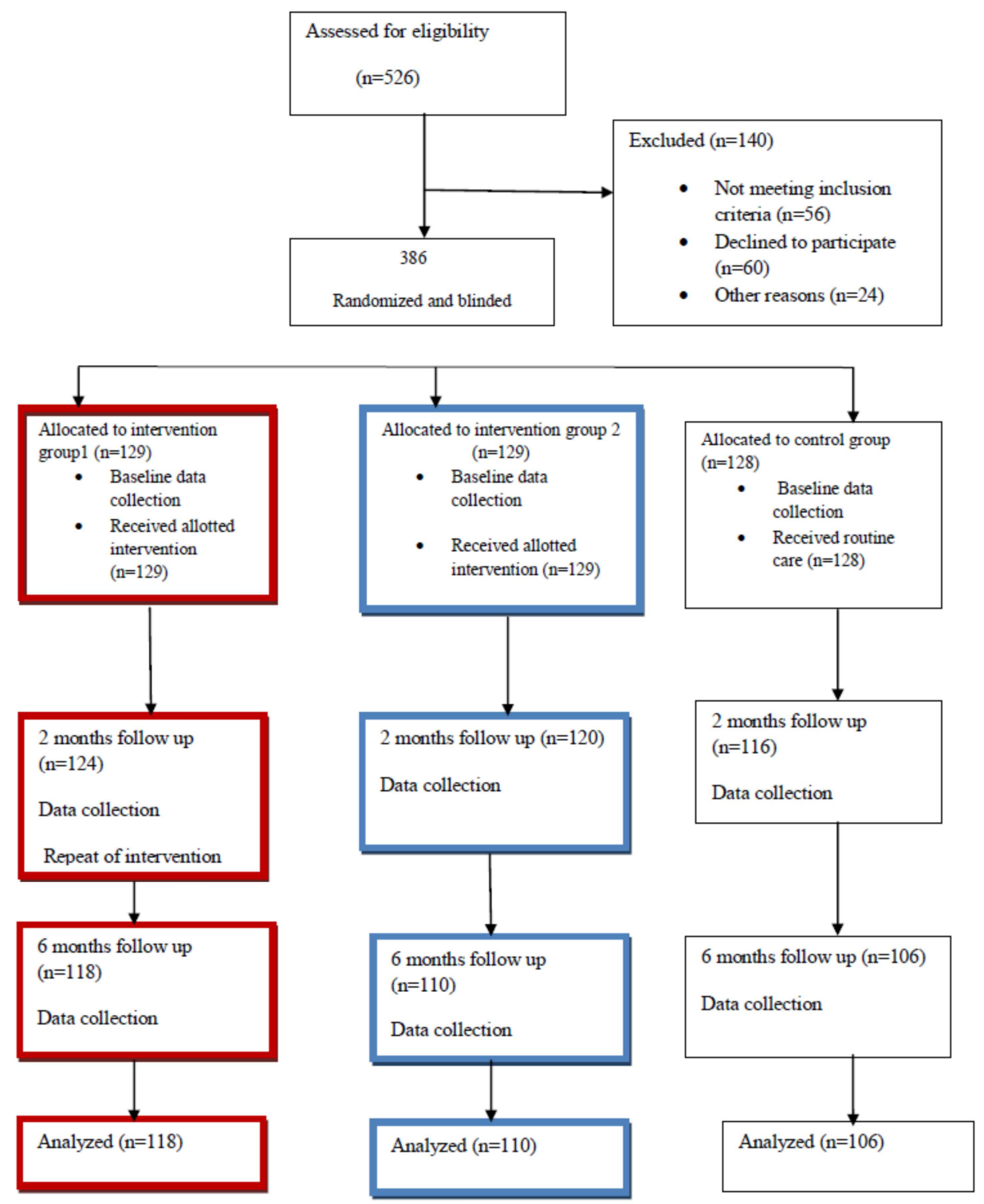

Figure 1. Flow diagram of patient participants in a randomized clinical trial conducted among HIV positive patient in all 4 comprehensive ART sites in Yola Nigeria.

Eligible patients who gave their consent were randomized and blinded. Opaque envelopes containing allocation color coded cards (white for 'controls' and pink for 'intervention group 1' and blue for 'intervention group 2' were used to execute the random assignment to the three groups so as to minimize allocation bias. A total of 386 color coded cards put in separate sealed opaque envelopes (129 pink cards, 129 blue cards and 128 white cards) where placed in a box and shuffled together. Under strict supervision a client was allowed to pick a single envelope and then proceeds to a consulting room as directed by a research assistant without opening the envelop. After every pick the remaining envelops were again reshuffled before the next supervised pick. At the exhaustion of all envelopes; Intervention group 1, intervention group 2 and the control group had a total of 129 , 129 and 128 patients respectively. On receipt of the sealed envelope the trained clinician opened it and used the color code to know which group the client belonged and so determined who was to and who was not to receive the intervention. 
A single blinded technique was employed with clients not knowing which group they belonged to. An initial code was given to every patient this was unique to the patient and included the comprehensive site of recruitment into the study, this code was maintained throughout the study and used to know clients who remained in the study or left the study. The presence of the cards on folders indicated the group of the client and so indicated the number of interventions to give or if no intervention was required.

To guide against interviewer and respondent bias, clinicians and clients in this study had a single contact (the clinician who had the initial client based counseling session with a patient was not involved in administering questionnaires, or repeating a counseling session to this client at follow up visit). After each encounter (counseling session or interview), every clinician signed on the color coded cards. This ensured a single contact between a clinician and client as the presence of a clinicians' signature on the coded card indicated he or she could no longer have any contact with that patient during the study period and thus the patient was seen by another clinician.

\subsection{Development of the CCC Counseling Module}

A counseling training module was developed and used to train the clinicians who delivered the intervention. This module was developed through the process of consultations with a group of experts. These included two experts in health education and promotion, an expert in behavioral intervention, two experts in infectious diseases and two consultants in public health. It was based on the IBM model [12] and had 5 sections;

Session 1 started the module with an overview of client centered counseling. Session 2 was on HIV knowledge on transmission and prevention. Session 3 was on the prevention of HIV sexual transmission with focus on multiple partners and condom use. Session 4 was on status disclosure and Session 5 on risk reduction counseling. Hand cards with diagrams for visual aided explanations were made available with the manual as counseling tools for use by clinicians during counseling sessions. A guide line check list of all areas of counseling was also constructed along with the training manual and was with each clinician at time of the intervention. The manual also had a questionnaire which served as a pre and post test for trainees.

\subsection{Intervention}

The intervention was a 10 to 15 minute clinic based one on one counseling session between a clinician (counselor) and a HIV positive adult patient (client). Counseling sessions were interactive allowing for listening, questions and answers. They were cultural sensitive and also consider issues related to gender and age. Areas covered during the brief counseling included; HIV transmission and prevention, healthy sexual practices, condom use, reduction in multiple sexual partners, beneficial disclosure, and individual risk assessment and reduction strategies.

\subsection{Data Collection}

A validated and pretested questionnaire was employed as the data collection tool. Questionnaires were interviewer administered and baseline data was obtained from all 386 respondents. The questionnaire was a modified version of those used by used by Carey, Morrison and Johnson (HIV knowledge and prevention) in 1997 [15], Misovich, Fisher and Fisher (A measure of AIDS prevention information, motivation, behavioral skills and behavior) in 1998 [16] and the AIDSCAPS/WHO/CAPS Counseling \& Testing Efficacy study: C \& T Baseline instrument of 1995 [17]. It consisted of 5 sections; Section 1 on socio-demographic variables, Section 2 consisted of questions on the knowledge of HIV transmission and prevention and had a total of 17 statements and answers that had the options of 'yes', 'no' and 'don't know'. Section 3 consisted of 5 statements to address patient's attitude towards HIV/AIDS. Answer options to these questions were from a 5 point Likert scale ranging from strongly agree, agree, don't know, disagree and strongly disagree. Section 4; addressed sexual behavior patterns and Section 5 addressed issues of status disclosure. The questionnaire was reviewed by a panel of experts who gave a consensus that existing items in the questionnaire were valid and measured knowledge on HIV transmission and prevention, attitudes of ART patients to HIV/AIDS, sexual behavior and status disclosure.

Reliability test for knowledge gave a Cronbach's alpha of 0.811 and that of attitude gave a Cronbach's alpha of 0.761

\subsection{Measurements}

Measurements were operational as follows: Independent variables which included age at last birthday later categorized in 10-year age brackets, gender, occupation, marital status and education that were nominally categorized. Primary outcome variables were HIV knowledge scores and attitudes towards HIV/AIDS scores (HIV attitude scores).

A correct response to a knowledge statement earned a mark of 1 and an incorrect response 0 . For the 5 point Lickert scale used, ranging from strongly disagree to strongly agree, a mark of 1 was awarded for strongly disagree, 2 for disagree, 3 for neutral, 4 for agree and 5 for strongly agree.

\subsection{Ethical Clearance}

Ethical approval was obtained from the University Human Research Ethics Committee of the Faculty of Medicine and Health Sciences University of Putra Malaysia before conducting the study. Ethical clearance was also obtained from the Health Research Ethics Committee of Federal Medical Centre Yola Nigeria. A written and signed informed consent was obtained from each participant. This written consent was made available in English, Hausa and Fulani (Hausa and Fulani being the two major native languages in Yola)

\subsection{Data Analysis}

Data was analyzed using SPSS version 22. HIV knowledge 
scores and attitude towards HIV/AIDS scores obtained were not normally distributed. The scores were initially reflected then a $\log 10$ data transformation was performed. One way ANOVA was used to compare log HIV knowledge scores and $\log$ attitudes towards HIV/AIDS scores among groups at baseline, 2 months and 6 months. Mixed design ANOVA was employed to look at the main effects of age, gender, centers (ART comprehensive sites), group, time and group - time interaction effects for log HIV knowledge scores and log attitudes towards HIV/AIDS scores. Test of significance was at $\alpha$ level 0.05 . A partial eta square $\left(\dot{\eta}^{2}\right)$ as a measure of effect size representing the variance in proportions of the dependent variable that can be explained by the independent variable was applied. The interpretation of the strength of eta squared values followed guidelines by Cohen, 1988 [18]: small effect (0.01), moderate effect $(0.06)$ and large effect $(0.14)$. All scores were added to give an aggregate score. Test of significance was at $\alpha$ level 0.05 . Primary outcome variables were knowledge on HIV transmission and prevention and attitudes towards HIV/AIDS.

\section{Results}

\subsection{Response Rate}

A total of $386 \mathrm{HIV}$ positive patients were recruited from all 4 comprehensive ART sites. At 2 months 360 patients were left in the study giving a response rate of $93.3 \%$. At the end of 6 months a total of 334 patients were left giving a response rate of $86.5 \%$. Of the 52 patients lost to follow up $27(51.9 \%)$ transferred out to ART clinics outside Yola, 12 $(23.1 \%)$ died and $13(25 \%)$ defaulted their routine clinic attendance during the period of the study.

\subsection{Baseline Socio-Demographic Variables}

Out of the 386 patient, $106(27.5 \%)$ were male. Most respondents 150 (38.9\%) were between the ages of 30 to 39 years though the youngest respondent was 18 years and the oldest 70 years. The largest indigenous tribe was the Bwatiye tribe consisting in total $70(20.5 \%)$ of respondents

Two hundred and ninety six $(76.9 \%)$ were from Adamawa state. Majority were married 207 (53.6\%) One hundred and thirty three $(34.5 \%)$ had attained tertiary education while $54(14.5 \%)$ had no form of education or were informally educated. Majority of respondents were civil servants (government employed); 102 (26.4\%).

Most respondents 207 (53.9\%) had known about their HIV status for less than three years with $377(97.7 \%)$ already on HAART. No significant difference was seen in the sociodemographic characteristics among the three study groups (Table 1).

Table 1. Socio-demographic characteristics by groups.

\begin{tabular}{|c|c|c|c|c|c|c|}
\hline \multirow{2}{*}{ Variables } & \multicolumn{3}{|c|}{ Frequency, n (\%) } & \multirow{2}{*}{ Total } & \multirow{2}{*}{ Test type } & \multirow{2}{*}{ p-value } \\
\hline & Intervention 1 & Intervention 2 & Control group & & & \\
\hline \multicolumn{7}{|l|}{ Age group (years) } \\
\hline$<30$ & $29(22.5)$ & $26(20.2)$ & $33(25.8)$ & $88(22.8)$ & \multirow{4}{*}{$\chi^{2}$} & \multirow{4}{*}{0.32} \\
\hline $40-49$ & $40(31.0)$ & $25(19.4)$ & $39(30.5)$ & $104(26.9)$ & & \\
\hline$\geq 50$ & $13(10.1)$ & $14(10.9)$ & $17(13.4)$ & $44(11.4)$ & & \\
\hline Total & $129(100.0)$ & $129(100.0)$ & $128(100.0)$ & $386(100.0)$ & & \\
\hline Mean, SD & $37.47(9.45)$ & $37.12(9.76)$ & $37.07(10.02)$ & $37.22(9.72)$ & $F$ & 0.94 \\
\hline \multicolumn{7}{|l|}{ Gender } \\
\hline Male & $38(29.5)$ & $32(24.8)$ & $36(28.1)$ & $106(27.5)$ & \multirow{3}{*}{$\chi^{2}$} & \multirow{3}{*}{0.70} \\
\hline Female & $91(70.5)$ & $97(75.2)$ & $92(71.9)$ & $280(72.5)$ & & \\
\hline Total & $129(100.0)$ & $129(100.0)$ & $128(100.0)$ & $386(100.0)$ & & \\
\hline \multicolumn{7}{|l|}{ Marital status } \\
\hline Single & $25(19.4)$ & $19(14.7)$ & $30(23.4)$ & $74(19.2)$ & \multirow[b]{3}{*}{$\chi^{2}$} & \multirow[b]{3}{*}{0.18} \\
\hline Married & $66(51.2)$ & $75(58.1)$ & $66(51.6)$ & $207(53.6)$ & & \\
\hline Divorced/ Separated & $15(10.9)$ & $16(12.4)$ & $9(7.1)$ & $39(10.1)$ & & \\
\hline Total & $129(100.0)$ & $129(100.0)$ & $128(100.0)$ & $386(100.0)$ & & \\
\hline \multicolumn{7}{|l|}{ Occupation } \\
\hline None & $20(15.6)$ & $35(27.2)$ & $39(30.5)$ & $94(24.4)$ & \multirow{7}{*}{$\chi^{2}$} & \multirow{7}{*}{0.32} \\
\hline Student & $6(4.7)$ & $9(7.0)$ & $7(5.5)$ & $22(5.7)$ & & \\
\hline Civil servant & $39(30.2)$ & $29(22.5)$ & $34(26.6)$ & $102(26.4)$ & & \\
\hline Business & $34(26.4)$ & $30(23.3)$ & $27(21.1)$ & $91(23.6)$ & & \\
\hline Farming & $9(7.0)$ & $9(7.0)$ & $8(6.3)$ & $26(6.7)$ & & \\
\hline Others & $21(16.3)$ & $17(13.2)$ & $13(10.2)$ & $51(13.2)$ & & \\
\hline Total & $129(100.0)$ & $129(100.0)$ & $128(100.0)$ & $386(100.0)$ & & \\
\hline \multicolumn{7}{|l|}{ Level of education } \\
\hline None/informal & 11(8.6) & $20(17.1)$ & $23(18.0)$ & $54(14.5)$ & \multirow{5}{*}{$\chi^{2}$} & \multirow{5}{*}{0.26} \\
\hline Primary & $36(28.0)$ & $17(13.2)$ & $24(18.8)$ & $77(19.9)$ & & \\
\hline Secondary & $38(29.5)$ & $45(34.9)$ & $37(29.0)$ & $120(31.1)$ & & \\
\hline Tertiary & $44(34.1)$ & $45(34.9)$ & $44(34.4)$ & $133(34.5)$ & & \\
\hline Total & $129(100.0)$ & $129(100.0)$ & $128(100.0)$ & $386(100.0)$ & & \\
\hline
\end{tabular}

Chi square test $\left(\chi^{2}\right)$ One way ANOVA $(F)$ test

Significant at $\mathrm{p}<0.05$ 


\subsection{Baseline HIV Knowledge and Attitudes Towards HIV/AIDS}

At baseline no significant difference was seen among the mean scores of log HIV knowledge and HIV attitude the 3 groups. (Table 2)

Table 2. Baseline comparison on mean scores of log HIV knowledge and log HIV attitude of intervention group 1 , intervention group 2 and control group.

\begin{tabular}{lllll}
\hline \multirow{2}{*}{ Outcome measures } & Mean (SD) & & Control group & Total \\
\cline { 2 - 3 } & Intervention 1 & Intervention 2 & & \\
\hline All $(\mathrm{n}=386)$ & & & & \\
Knowledge & $0.57(0.28)$ & $0.56(0.29)$ & $0.57(0.30)$ & $0.57(0.29)$ \\
Attitude & $0.60(0.38)$ & $0.53(0.35)$ & $0.63(0.34)$ & $0.59(0.36)$ \\
\hline
\end{tabular}

$\mathrm{p}$ value calculated using One way $\operatorname{ANOVA}(\mathrm{F})$ test

*significant at $\mathrm{p}<0.05$

\subsection{Analysis of Effectiveness of CCC Counseling on Knowledge on HIV Transmission and Prevention}

At 2 months a significant difference was seen among the means of the log HIV knowledge scores of the 3 groups (F $(2,357)=6.295, \mathrm{p}=0.002)$. Following the back transformation of the log HIV knowledge scores, post hoc analysis showed a significantly higher mean HIV knowledge score in intervention group 2 compared to the control group (15.82 vs $15.05, \mathrm{p}=0.002)$.

At 6 months a significant difference was seen among the means of the log HIV knowledge scores of the 3 groups (F $(2,331)=36.858, p=0.001)$. Following the back transformation of the log HIV knowledge scores, post hoc analysis showed there was a significantly higher mean HIV knowledge score in intervention group 1 compared to the control group (16.52 vs $15.92, \mathrm{p}=0.0001)$. A significantly higher mean HIV knowledge score was seen between intervention group 1compared to intervention group 2 (16.52 vs $14.84, p-0.001)$ and similarly a significantly higher mean HIV knowledge score was seen between intervention group 2 compared to the control group (15.92 vs $14.84, \mathrm{p}=0.0001)$.

Table 3 shows the summary of between subjects and within subject effects for the log HIV knowledge scores. A significant difference was seen among the 3 groups ( $\mathrm{p}=$ $0.0001)$. There was significant main effect for time $(\mathrm{p}=$ $0.0001)$. There was a significant interaction effect between group and time; $(\mathrm{p}=0.015)$. No significant effects were seen for age ( $\leq 44$ years and $\geq 45$ years), gender and in the centers for mean log HIV knowledge scores.

Table 3. Summary table of mixed design ANOVA for mean log HIV knowledge scores.

\begin{tabular}{|c|c|c|c|c|c|c|}
\hline $\begin{array}{l}\text { Source } \\
\text { Log of HIV knowledge scores }\end{array}$ & Type III sum of squares & df & Mean square & $\mathbf{F}$ & p value & Partial $\dot{\eta}^{2}$ \\
\hline Group & 1.279 & 2 & 0.638 & 7.557 & $0.001^{*}$ & 0.049 \\
\hline Gender & 0.022 & 1 & 0.022 & 0.261 & 0.610 & 0.001 \\
\hline Age & 0.010 & 1 & 0.010 & 0.015 & 0.734 & 0.001 \\
\hline Center & 0.263 & 3 & 0.088 & 1.038 & 0.376 & 0.011 \\
\hline Group*gender & 0.054 & 2 & 0.027 & 0.329 & 0.720 & 0.002 \\
\hline Group*age & 0.207 & 2 & 0.104 & 1.226 & 0.295 & 0.008 \\
\hline Center*group & 0.194 & 6 & 0.032 & 0.382 & 0.890 & 0.008 \\
\hline Center*gender & 0.417 & 3 & 0.139 & 1.646 & 0.179 & 0.017 \\
\hline Center*age & 0.264 & 3 & 0.088 & 1.043 & 0.374 & 0.011 \\
\hline Group*gender*age & 0.054 & 2 & 0.027 & 0.322 & 0.725 & 0.002 \\
\hline Group*center*gender*age & 0.037 & 2 & 0.019 & 0.222 & 0.801 & 0.002 \\
\hline Error(between) & 24.746 & 293 & 0.084 & & & \\
\hline Time & 3.396 & 1 & 3.396 & 38.968 & $0.0001 *$ & 0.117 \\
\hline Time*age & 0.163 & 1 & 0.163 & 1.873 & 0.172 & 0.006 \\
\hline Time*center & 0.057 & 3 & 0.019 & 0.216 & 0.885 & 0.002 \\
\hline Time*group*gender & 0.081 & 2 & 0.041 & 0.465 & 0.628 & 0.003 \\
\hline Time*group*age & 0.189 & 2 & 0.094 & 1.084 & 0.340 & 0.007 \\
\hline Time*center* group & 0.090 & 6 & 0.015 & 0.173 & 0.984 & 0.004 \\
\hline Time*sex*group & 0.082 & 2 & 0.041 & 0.465 & 0.628 & 0.003 \\
\hline Time*group*gender*age & 0.022 & 2 & 0.011 & 0.124 & 0.883 & 0.001 \\
\hline Time*center*group*gender*age & 0.103 & 2 & 0.051 & 0.589 & 0.556 & 0.004 \\
\hline Error(within) & 25.531 & 586 & 0.092 & & & \\
\hline
\end{tabular}

ANOVA; Analysis of variance

df; degree of freedom

*significant at $<0.05$ 


\subsection{Analysis of Effectiveness of CCC Counseling on Attitudes Towards HIV/AIDS}

No statistical difference was seen among the means of the $\log$ HIV attitude scores of the 3 groups at base line; F (2, $383)=2.841, \mathrm{p}=0.060$. At 2 months there was no significant difference among the means of the log HIV attitude scores of the 3 groups; $F(2,357)=2.996, p=0.051$.

At 6 months there was a statistical difference among the means of the log HIV attitude scores of the 3 study groups; F $(2,331)=10.583, p=0.0001$. Following the back transformation of the log HIV attitude scores, post hoc analysis showed there was a significantly higher mean HIV attitude score in intervention group 1 compared to intervention group $2(24.10$ vs $22.99, \mathrm{p}=0.0001)$. There was also a significantly higher mean HIV attitude score in intervention group 1 compared to intervention group 2 (24.10 vs $23.25, \mathrm{p}=0.001)$. No significant difference was seen between intervention group 2 and the control group (23.25 vs $22.99, \mathrm{p}=0.831$ ).

Table 4 shows the summary of between subjects and within subject effects for log HIV attitude scores. There was a significant main effect for groups $(p=0.021)$ and time $(p=$ $0.0001)$. The main effect of group - time interaction was not significant $(p=0.100)$. No significant effects were seen for age ( $\leq 44$ years and $\geq 45$ years), gender and in the centers for mean $\log$ attitude scores.

Table 4. Summary table of mixed design ANOVA for log attitude scores towards HIV/AIDS.

\begin{tabular}{|c|c|c|c|c|c|c|}
\hline Source & Type III sum of sauares & Df & Mean square & $\mathbf{F}$ & n value & Partial $\dot{n}^{2}$ \\
\hline Log attitude scores to HI V/AIDS & & & & & & \\
\hline Group & 1.006 & 2 & 0.503 & 0.897 & $0.021 *$ & 0.026 \\
\hline Gender & 0.130 & 1 & 0.130 & 1.006 & 0.317 & 0.003 \\
\hline Age & 0.444 & 1 & 0.444 & 3.439 & 0.065 & 0.012 \\
\hline Group*gender & 0.026 & 2 & 0.013 & 0.100 & 0.904 & 0.001 \\
\hline Group*age & 0.143 & 2 & 0.071 & 0.561 & 0.571 & 0.003 \\
\hline Gender*age & 0.229 & 1 & 0.229 & 1.801 & 0.181 & 0.006 \\
\hline Group*gender*age & 0.179 & 2 & 0.089 & 0.693 & 0.501 & 0.005 \\
\hline Center*group & 0.306 & 6 & 0.051 & 0.395 & 0.882 & 0.008 \\
\hline Center*gender & 0.255 & 3 & 0.085 & 0.658 & 0.578 & 0.007 \\
\hline Center*age & 0.065 & 3 & 0.022 & 0.168 & 0.918 & 0.002 \\
\hline Center*gender*age & 0.201 & 2 & 0.100 & 0.777 & 0.461 & 0.005 \\
\hline Group*center*gender*age & 0.243 & 2 & 0.221 & 0.942 & 0.391 & 0.006 \\
\hline Error(between) & 37.811 & 293 & 0.129 & & & \\
\hline Time & 2.972 & 2 & 1.486 & 14.066 & $0.0001 *$ & 0.046 \\
\hline Group*time & 0.399 & 4 & 0.100 & 0.945 & 0.437 & 0.006 \\
\hline Time* gender & 0.376 & 2 & 0.188 & 1.799 & 0.170 & 0.006 \\
\hline Time*center & 0.704 & 6 & 0.117 & 1.110 & 0.355 & 0.011 \\
\hline Time*age & 0.222 & 2 & 0.111 & 1.050 & 0.351 & 0.004 \\
\hline Time*age*gender & 0.200 & 2 & 0.100 & 0.948 & 0.388 & 0.003 \\
\hline Time*centre*group & 0.879 & 12 & 0.073 & 0.693 & 0.759 & 0.014 \\
\hline Time*group*gender*age & 0.450 & 4 & 0.113 & 1.053 & 0.379 & 0.006 \\
\hline Time*center*group*gender*age & 0.135 & 4 & 0.034 & 0.319 & 0.865 & 0.002 \\
\hline Error (within) & 61.899 & 586 & 0.106 & & & \\
\hline
\end{tabular}

ANOVA; Analysis of variance

df; degree of freedom

*significant at $<0.05$

\section{Discussion}

\subsection{Effectiveness of CCC Counseling on Knowledge of HIV Transmission and Prevention}

Significantly higher HIV knowledge scores of intervention group 1 compared to the control group at 2 months and similar significantly higher HIV knowledge scores of group 1 compared to the intervention group 2 and the control group at 6 months indicates that the $\mathrm{CCC}$ counseling was effective in improving HIV knowledge of the respondents who received it twice.
The results of the mixed design ANOVA performed on the HIV knowledge scores showing a significant difference among the 3 study groups indicates a difference among the groups for respondents who did not receive the CCC counseling (control group), the group that received the CCC counseling twice (intervention group 1) and that which received the CCC counseling once (intervention group 2). A significant main effect for time indicates a change in the HIV knowledge scores over time (baseline to 2 months and then to 6 months) with a large effect size further indicating that implementation of the CCC counseling would detect a large improvement in HIV knowledge of the respondents who 
receive it. A significant interaction effect between group and time; though with a small effect size, indicates that implementation of the CCC counseling would detect an improvement in HIV knowledge among respondents even by a small magnitude of difference.

No interaction effects of age and gender on knowledge scores indicates that improvement in the HIV knowledge seen in the respondents was not dependent on the gender or the age ( $\geq 45$ years or $<45$ years) of the respondents. No interaction effects for the centers on the HIV knowledge scores indicates that a clients' improved knowledge on HIV prevention and transmission was not dependent on which ART site he or she was enrolled in care in Yola.

Counseling as an intervention has been reported to be effective in improving sexual behaviors among PLWHAs, such behaviors include; condom use and multiple sexual partners. $[19,20,21]$ Though this research did not assess the effectiveness of counseling on sexual behaviors among PLWHAs, it assessed the effectiveness of counseling on HIV knowledge and attitudes towards HIV/AIDS among the same group of individuals; similar positive findings have shown that it is an effective intervention tool in improving HIV knowledge and attitudes of those living with the disease.

The findings of this research are similar to studies that showed positive effects of educative interventions on HIV knowledge. A study by Adeomi et al conducted among inschool adolescents to determine the effectiveness of a peer education intervention in improving HIV knowledge, attitudes and preventive practices in Osun state in western Nigeria, reported a significant increase in good HIV knowledge from $50.0 \%$ to $86.7 \%$ among respondents who received the intervention [9].

Still in Africa, a study carried out among police service employees in South Africa, reported that there was a significant change in HIV knowledge of employees that attended a one day HIV/AIDS awareness workshop [22]. Though this study was conducted among people who were HIV negative or of unknown status and type of intervention received was a single dose in form of a workshop, improvements in HIV knowledge are similar to the findings of this research.

A school based intervention conducted in Wuhan, China involving 3 middle schools and 2 high schools in which the intervention was a one-class education program about HIV/AIDS; findings showed that all students had significant improvements in knowledge about HIV [23] Findings of this study are similar to the findings of this research with respect to improvements in HIV knowledge of participants who received the intervention though the intervention type is different. This research used a clinician client based counseling and respondents all HIV positive adults.

\subsection{Effectiveness of CCC Counseling on Attitudes Towards HIV/AIDS}

No significant difference seen among the 3 study groups at 2 months indicates that at 2 months no measurable effectiveness of the CCC counseling could be seen in the attitudes of the respondents. The CCC counseling could be considered to be more effective at improving attitudes towards HIV/AIDS when given twice than once since significant higher mean attitude log scores were seen for intervention group 1 compared to intervention group 2 at 6 months.

Mixed design ANOVA results showing a significant main effect for groups indicates changes in log attitude scores of the 3 study groups that were brought about by the intervention. A significant main effect for time indicates change in the log attitude scores over time. The small effect size indicates that implementation of the intervention would detect an improvement in the attitude towards HIV/AIDS of respondents by a small magnitude of difference.

The significant mean difference of intervention group 1 compared to the control group is indicative of the effectiveness of the CCC counseling at improving the attitudes towards HIV/AIDS of respondents who had received it. No significant mean differences between intervention group 1 and intervention group 2 indicates that giving the intervention twice or once showed no difference in the effectiveness of the intervention on attitudes towards HIV/AIDS.

No interaction effects of age and gender on the HIV attitude scores indicates that improvement in attitudes towards HIV/AIDS seen in the respondents was not dependent on the gender (male or female) or the age ( $\geq$ 45 years or $<45$ years) of the respondents. No interaction effects for the centers on the HIV attitude scores indicates that a clients' improved attitude towards HIV/AIDS was not dependent on which ART site he or she was enrolled in care in Yola.

Similar improvement in attitudes were reported by Adeomi and his group; in which recipients of a peer education intervention had significant increase in their positive attitudes towards HIV/AIDS after receiving the intervention. [9] Though type of intervention in this study differs from that of this research along with the fact that participants in the study are of unknown HIV status, similar positive effects were seen in both groups.

The study by Gao et al also reported significant positive changes in the attitudes towards HIV/AIDS of students who received a one class education program about HIV/AIDS. [23] Again positive findings reported in this study are similar to the findings of this research but recipients and type of intervention differ.

No significant change in attitude towards HIV/AIDS was reported among recipients of a one day HIV/AIDS awareness workshop, where it was also recommended that a one day workshop was not enough to change attitudes [22]. The finding of this study is similar to this research as no positive change in attitude was seen in those who received the intervention once (intervention group 2) when compared to the control group. Findings of this research indicated that the intervention was more effective in those who received it twice.

Strengths of this study include; the random selection of the study sample as well as the random allocation to the different 
arms of the study that helped to overcome threats of selection bias. The threats to validity were also minimized by the use of randomization to the treatment groups. Blinding of respondents in this study helped to reduce response bias. Ensuring a single contact between a clinician and respondent throughout the length of the study further helped to reduce response and interviewer bias. The effects of different doses levels of the intervention was made possible with intervention group 1 having 2 doses, intervention group 2 having a single dose and the control group receiving routine care. Use of trained clinicians to deliver the intervention had the benefit of increasing and improving their involvement in the counseling process. The use of Mixed - design ANOVA allowed for a combination of fixed effects, random effects and a repeated measure in the analysis.

Study limitations include the fact that recruitment of both cases and controls from same ART sites could have increased the chance of cross contamination. Though patients were sampled from the 4 ART comprehensive sites in Yola, this may not be fully representative of all persons living with HIV/AIDS in Yola as due to stigma and discrimination a significant number of patients still access ART services elsewhere. With the questionnaire as the tool of data collection, a lot depended on the truthfulness of respondents. The use of interviewer administered questionnaires (due to the literacy level of some respondents) and lack of anonymousity may have further affected the responses of respondents. Being a single blind study the interviewers (clinicians) are prone to some interviewer bias. The log transformation performed on obtained data could bring about difficulties in result interpretations.

\section{Conclusion}

Clinician client centered counseling is effective in improving HIV knowledge and attitudes towards HIV/AIDS of adult patients living with HIV. Implementing clinician client based counseling in other ART sites is thus recommended as significant improvements in knowledge and attitudes would be expected in those patients who receive the counseling and thus would serve as a positive preventive strategy.

\section{Acknowledgements}

The authors would like to acknowledge the hospital management and ART Unit staff of the FMC Yola, SSHY, St Francis Jambutu and Adamawa Hospital. Special thanks go to Dr Ali Danburam the Medical Director of FMC Yola. Also acknowledged are the members of the research team; Dr Edwin Habila, Dr Maurice Solomon, Dr Abdulrahman Mohammed, Dr Barnabas Dongonyaro, Dr Mamza Jabani, Dr Temilade Adenle, Dr Jeff Ijafu Samuel, Dr Cyril Jomusu Awhoyo, Dr Benjamin Yakubu and Dr Timothy Williams Tizhe. Other acknowledged contributors to this research work are; Grace Oluchi Enwereuzo, Glory Haniel and Kingsley Cyprain Margson.

\section{References}

[1] Joint United Programme on HIV/AIDS (UNAIDS); 2012. UNAIDS report on global AID Sepidemic. http://www.unaids.org/en/media/unaids/contentassets/docume nts/epidemiology/2012/gr2012/2012. Accessed March 2013.

[2] Federal Ministry of Health; 2010. National HIV Seroprevalence Sentinel Survey.www.nigeria-aids.org/ accessed August 2012.

[3] Nigeria UNAIDS.

http://www.unaids.org/en/regionscountries/countries/nigeria. Accessed March 2013.

[4] Dibua U. HIV/AIDS Fact sheet - Predisposing Factors the Nigeria Situation. Population Reference Bureau 2009. www.intechopen.com. Accessed December 2013.

[5] National Reproductive Health Survey (NARHS) 2007. http://thedata.harvard.edu/dvn/dv/Nigeria/faces/study/StudyPa ge.xhtml accessed December 2013.

[6] Asekun-Olarinmoye EO and Oladele EA. Condom use among undergraduates in Osun state, Nigeria: Implications for sexually transmitted infections (STIs)/HIV prevention. Res Jour Med Sci. 2009; 3: 179-187.

[7] Fawole AO, Ogunkan DV and Adegoke GS. Sexual behaviour and perception of HIV/AIDS in a Nigerian tertiary institution; University of Ilorin, a case study. Global Journal of Human Social Science. 2011; 11:65-71.

[8] Osonwa OK, Ogbuagu UR, Iyam MA, Osuchukwu NC, Eko JE, Achoakawa CE, Osonwa RH, Asuquo OD and Onovo AA. Knowledge, attitudes and risk perception among youths in Calabar, Cross Rivers state, Nigeria. Journal of Hummanities and Social Science. 2013; 7: 01-08

[9] Adeomi AA, Adeoye OA, Asekun-Olarinmoye EO, Abodunrin OL, Olugbenga-Bello AI and Sabageh AO. Evaluation of the effectiveness of peer education in improving HIV knowledge, attitudes and sexual behaviours among in -school adolescents in Osun state Nigeria. AIDS Research and Treatment 2014; Article ID 131756. http://dx.doi.org/10.1155/2014/131756.

[10] Martins OF, Rampal L, Munn-Sann L, Sidiks SM, Othman N, Iliyasu $\mathrm{Z}$ and Salawu FK. Knowledge and attitudes of adult HIV Positive Patients to HIV/AIDS in Selected ART Clinics in Yola, Nigeria. Malaysian Journal of Medicine and Health Sciences 2015; 11(2):35-45

[11] Martins OF, Rampal, L, Munn-Sann L, Sidk SM, Othman N, Iliyasu Z and Salawu FK. Sexual behaviors and status disclosure of Adult HIV Positive Patients Enrolled in Care in Yola, Nigeria. International Journal of Health Science Research 2016; 6(3):6-15.

[12] Fisher JD and Fisher WA. Changing AIDS- risk behavior. Psychological Bulletin 1992; 111; 3:455-474.

[13] Lemeshow S, Hosmer DW, Klar J, Lwanga SK and World Health Organization. Adequacy of sample size in health $\begin{array}{llll}\text { studies. } & \text { WHO. } & \end{array}$ Http://www.who.int/iris/handle/10665/41607. accessed April 2013.

[14] Olowookere SA, Fatiregun AA and Adewole IF. Knowledge and attitudes regarding HIV/AIDS and antiretroviral therapy among patients at a Nigerian treatment clinic. J Infect Dev Ctries 2012; 6(11): 809-816. 
[15] Carey MP, Morrison- Beedy D and Johnson BT. The HIVKnowledge Questionnaire: Development and evaluation of a reliable, valid and practical self-administered questionnaire. AIDS Behav; 1997 1: 61-74.

[16] Misovich SJ, Fisher WA and Fisher JD. A measure of AIDS prevention information, motivation, behavioural skills and behaviour. IN Davis CM, Yarber WH, Bauser R, Scheer G. and Davis SL. (Eds), Handbook of sexuality related measures 1998 pp 328-337. Sage Publishing.

[17] AIDSCAP/WHO/CAPS counseling \& Testing Efficacy study: $\mathrm{C} \&$ \& $\mathrm{T} \quad$ Baseline Instrument. http://caps.ucsf.edu/resources/survey-instruments. Accessed March 2013

[18] Cohen, J. Statistical power analysis for the behavioral sciences. $2^{\text {nd }}$ ed. 1998 New Jersy: Erlbaum.

[19] Patterson TL, William SS and Semple SJ. Reducing the sexual risk behaviors of HIV + individuals: Outcome of a randomized clinical trial. Ann Behav Med. 2003; 25:137-145.
[20] Metcalf CA, Malotte CK, Douglas JM, Paul SM, Dillon BA, Cros $\mathrm{H}$, et al. Efficacy of a booster counseling session 6 months after HIV testing and counseling: A randomized clinical trial (RESPECT-2). Sex. Trans.Dis. 2005; 32: 123129.

[21] Fisher JD, Fisher WA, Cornman DH, Amico RK, Bryan A and Gerald HF. Clinicians -delivered interventions during routine clinical care reduces unprotected sexual behavior among HIVinfected patients. Jour Acquir Immune Def Synd. 2006; 41:4445.

[22] Cherian L and Maphoso LS. Measurement of the effectiveness of an HIV/AIDS intervention program on knowledge, attitudes and behaviour of the South African polise service employees, Curatonis; 2009; 32: 4-18.

[23] Gao X, Wu Y, Zhang Y, Zhang N, Tang J, Qui J, Lin X and Du Y. Effectiveness of school based education on HIV/AIDS knowledge, attitudes and behaviour among secondary school students in Wuhan, China. Plos one; 2014; 7: e44881.doi:10.1371/journal.pone.0044881. 